WellBeing International

WBI Studies Repository

6-1986

\title{
Variation in Piglet Weights: Development of Within-Litter Variation Over a 5-Week Lactation and Effect of Farrowing Crate Design
}

\author{
B. K. Thompson \\ Agriculture Canada \\ D. Fraser \\ Agriculture Canada
}

Follow this and additional works at: https://www.wellbeingintlstudiesrepository.org/ontoge

Part of the Animal Studies Commons, Developmental Biology Commons, and the Other Animal

Sciences Commons

\section{Recommended Citation}

Thompson, B. K., \& Fraser, D. (1986). Variation in piglet weights: development of within-litter variation over a 5-week lactation and effect of farrowing crate design. Canadian Journal of Animal Science, 66(2),

361-372.

This material is brought to you for free and open access by WellBeing International. It has been accepted for inclusion by an authorized administrator of the WBI Studies Repository. For more information, please contact wbisr-info@wellbeingintl.org.

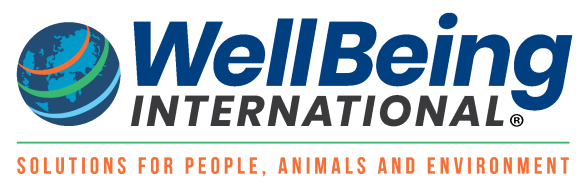




\title{
Variation in Piglet Weights: Development of Within-Litter Variation Over a 5-Week Lactation and Effect of Farrowing Crate Design
}

\author{
B.K. Thompson and David Fraser \\ Agriculture Canada
}

\begin{abstract}
KEYWORDS
piglet, body weight, suckling behavior, sow, farrowing crate design, litter size

ABSTRACT
\end{abstract}

\begin{abstract}
Piglets from 51 litters were weighed weekly over a 5-wk lactation in an experiment that studied the effects of farrowing crate design and other factors on variation in piglet weight. Of two farrowing crates used, one had low horizontal bars that tended to impede access to the upper row of teats, while the other had angled vertical bars which permitted freer access. Fourteen-day weights were more uniform in the vertical-bar crates than in the horizontal-bar crates $(P<0.025)$, but the difference waned by day $35(P>0.05)$. There were no significant differences in mean body weight owing to crate type $(P<0.05)$ for any of the weekly measurements but, by day 14 , there was a significant linear trend $(P<0.05)$ at decreasing main body weight with increasing litter size. The interaction between crate type and litter size was significant at the later ages $(P<0.01$ at day 35$)$ because the linear trend was more pronounced for horizontal-bar crates than for vertical. Litters differed greatly in the uniformity of their body weights. Much of the variation became established in the first and, to a lesser extent, the second week after birth. In those weeks, weight gains were highly variable and were not closely related to weight at the beginning of the week. Thereafter, the established differences tended to be perpetuated to $35 \mathrm{~d}$, because weight gains were largely proportional to body weight. Within-litter competition appeared to influence weight gain considerably.
\end{abstract}

"It would simplify management a great deal if pigs in a litter were like 'peas in a pod' at weaning." In contrast to this happy ideal expressed by English et al. (1917), many litters of pigs have extremely variable weaning weights, with the largest piglets weighing two to three times more than their smallest litter-mates. Such lack of uniformity can complicate management, and is thought to contribute to piglet deaths (English et al. 1917; Zschorlich and Ritter 1984).

In a previous experiment (Fraser and Thompson 1986), it was noticed that, in farrowing crates in which the lower bars interfered with the piglets' access to some of the teats, weight gains of litter-mate piglets (at $14 \mathrm{~d}$ ) were considerably less uniform than in crates allowing better access to the teats, even though average weight gain seemed unaffected. The experiment reported here was designed to extend this comparison of crate design by studying weights over a 35-d lactation and by using sows of third or later parity instead of the smaller first- and second-parity sows studied previously. 
In addition, the weekly weighing of about 500 piglets provided an opportunity to explore various aspects of piglet weight gains. The issues considered here include the development of within-litter variation over the course of the lactation, and the effect of competition among litter-mates on their weight gains.

\section{METHODS}

The experiment initially involved 54 litters of Yorkshire pigs from the specific-pathogen-free herd of the Animal Research Centre, Ottawa. The farrowing facilities have been described by Fraser and Thompson (1986). They consisted of six rooms, each with six pens containing identical farrowing crates constructed of round galvanized tubing ( $32 \mathrm{~mm}$ outside diameter) using a common commercial design. Each side of the crate consisted of three horizontal bars located 970,690 and $410 \mathrm{~mm}$ above the floor, and a fourth horizontal bar that could be positioned 200,250 or $300 \mathrm{~mm}$ above the floor. The lowest bar was set at the highest position that still prevented the sow from becoming lodged underneath. This was normally the 250-mm position. The sides of the crate were $620 \mathrm{~mm}$ apart (outside dimension), leaving an inside dimension of $560 \mathrm{~mm}$ between each pair of horizontal bars. The crates were converted to a "vertical-bar" design by removing the lowest horizontal side bar and installing tubular vertical bars (normally three on each side of the crate). The bars flared outward from the sow at an angle of 25 degrees to the vertical, and thus resembled the "prongs" or "fingers" on commercially-available farrowing crates of this type (see Fraser and Thompson (1986) Fig. 1).

Sows were moved into farrowing crates about $5 \mathrm{~d}$ before farrowing was due. Crates were filled as they became available, and were then converted to horizontal or vertical bars as stipulated by a randomization scheme designed to avoid systematic confounding of crate type with any position or room effects. In most cases, the natural litter size of the sow (after any necessary culling of piglets) was retained, but fostering or removal of piglets was used toward the end of the experiment in an attempt to have at least five litters of each litter size $(8,9,10,11,12)$ for each type of crate.

Piglets were weighed (to the nearest $10 \mathrm{~g}$ ) on days $0,7,14,21,28$ and 35 after birth. The 0-d weights were taken $4-24 \mathrm{~h}$ after birth, at which time any culling or fostering was completed. Piglets with physical abnormalities or weighing $<800 \mathrm{~g}$ were removed. Apart from this, any piglets to be removed were chosen at random. The 12 piglets added by fostering (from other litters in the herd) were within the weight range of the recipient litter and differed in age from the recipient litter by no more than $1 \mathrm{~d}$. Water was available to the piglets from birth, and creep feed from $10 \mathrm{~d}$ of age. Males were castrated at $10 \mathrm{~d}$ of age.

\section{Statistical Analysis}

Differences between litters were tested by analysis of variance using a model of the form

$$
Y=\mu+s_{\mathrm{i}}+c_{\mathrm{j}}+(s c)_{\mathrm{ij}}+e_{\mathrm{ijk}}
$$

where $\mu$ represents the overall mean; $s_{\mathrm{i}}$ represents litter size $\left(8,9,10,11\right.$ or 12 piglets); $c_{\mathrm{j}}$ represents crate type (horizontal or vertical bars); $(s c)_{\mathrm{ij}}$ the interaction of size and crate type; and $e_{\mathrm{ijk}}$ the random component for the $k^{\text {th }}$ litter of the $i j$ th group. It was thought that impeded access to the udder caused by the horizontal bars might influence piglet performance and consequently mean litter weight and/or withinlitter variation in body weight. Hence, analyses of variance were applied to both litter means and variances. In these analyses, the means and variances were not weighted according to litter size in order that equal emphasis could be given to each litter size. Under the usual assumption of normality for the error in the linear model, within-litter variance would not be normally distributed. In order that the distribution of these variances more closely approximated the normal distribution, the log transformation 
was applied to the variances before calculating the analysis of variance. However, for clarity of presentation, the means of untransformed values are shown in the tables.

Initial weights of the piglets could not be controlled in the experiment, but were expected to influence subsequent performance (both litter means and variances). Consequently, 7- to 35-d weights for each piglet were adjusted for initial (day 0 ) weight, using the regression coefficients obtained from analysis of covariance, before analyses of variances were applied to litter means and variances. Aside from eliminating some of the impact of differing litter size on litter means, this step also effectively removed an apparent correlation between within-litter variance at day 0 and that at later ages. Tests of heterogeneity of regression slopes (Snedecor and Cochran 1961, p. 432) among litter sizes and between crate types were carried out, but no evidence was found to prevent using the average slope in making the adjustments.

Analysis of variance of individual piglet weights was used to identify any effects of sex and fostering on piglet performance. Regression analyses were also carried out on individual weights when considering percentage of overall variation explained by initial weight. Tests of regression slopes among and within litters followed the methodology described by Snedecor and Cochran (1961, p. 436).

\section{RESULTS}

Three litters were omitted from the analysis (two from vertical-bar crates, one from horizontal) because the sows became ill or because the piglets were found to have physical abnormalities that had been overlooked when the litter was assigned to the treatment. Of the remaining 508 piglets, 20 died between days 0 and 35, 12 in litters with vertical bars and 8 in litters with horizontal bars. These animals were omitted from the analysis. Six piglets died within $4 \mathrm{~d}$ of farrowing; in these cases, litter size was reclassified to exclude the dead animal. After reclassification, several levels of litter size and crate type had fewer than the intended minimum of five litters (Table 1).

Analysis of variance of individual piglet weights showed no significant differences between males and females at any age. On average, the 12 fostered piglets were slightly lighter than the others on day 0 (1.28 vs. $1.37 \mathrm{~kg}: P<0.05)$, but the difference was no longer significant $(P>0.05)$ by day 7 . Because the effects were small, sex and fostering were ignored in subsequent analyses.

\section{Effect of Farrowing Crate Design and Litter Size}

Mean body weight of the 51 litters on day 0 (Table 1) showed no substantial differences attributable to crate type, litter size or the interaction ( $F<1.0$ in all cases). By day 14, body weight (adjusted for initial weight) showed a significant linear trend associated with litter size $(P<0.05)$, with smaller litters having larger weights. The magnitude of this trend increased as the piglets grew older, and was highly significant by day $35(P<0.005)$. By day 21 , there was also an interaction $(P<0.025)$ between crate type and the linear effect of litter size. The interaction reflected a tendency for mean body weight to decline with increasing litter size in horizontal-bar crates but not in vertical. This interaction increased in magnitude as the piglets grew older $(P<0.01$ at day 35). Averaging over all litter sizes, mean 35-d weight, adjusted for initial weight, was $9.70 \mathrm{~kg}$ with vertical bars and $9.61 \mathrm{~kg}$ with horizontal $(P>0.05)$.

Analysis of variance of within-litter variance (after applying the log transformation) showed no significant differences $(P>0.05)$ attributable to crate type, litter size, or interaction on day 0 (Table 2). At subsequent ages, variance tended to be larger in litters in crates with horizontal bars. The $F$-ratio representing the difference in variance between crate types approached statistical significance at $7 \mathrm{~d}(P<0.10)$, and was largest at $14 \mathrm{~d}(P<0.025)$. At this age, mean within-litter variance was 0.343 with vertical bars and 0.530 with horizontal bars. The $F$-ratio became smaller at 21 and $28 \mathrm{~d}(P<0.10$ and $P<0.05$, respectively), 
and was no longer significant at $35 \mathrm{~d}(P>0.05)$. Litter size did not seem to affect within-litter variance, nor was there an interaction of litter size and crate type at any age.

Table 1

Mean† piglet body weight $(\mathrm{kg})$ at $0,7,14,21,28$ and $35 \mathrm{~d}$ (after adjusting 7- to 35-d weights for 0-d weight)

\begin{tabular}{|c|c|c|c|c|c|c|c|c|c|c|c|c|c|c|}
\hline \multirow[b]{2}{*}{ Litter size } & \multicolumn{2}{|c|}{ No. of litters (n) } & \multicolumn{2}{|c|}{ Day 0} & \multicolumn{2}{|c|}{ Day 7} & \multicolumn{2}{|c|}{ Day 14} & \multicolumn{2}{|c|}{ Day 21} & \multicolumn{2}{|c|}{ Day 28} & \multicolumn{2}{|c|}{ Day 35} \\
\hline & $\mathrm{H} \ddagger$ & V & $\mathbf{H}$ & V & $\mathbf{H}$ & $\mathbf{V}$ & $\mathbf{H}$ & V & $\mathbf{H}$ & $\mathbf{V}$ & $\mathbf{H}$ & V & $\mathbf{H}$ & V \\
\hline 8 & 7 & 5 & 1.47 & 1.44 & 2.55 & 2.43 & 4.35 & 3.98 & 6.17 & 5.47 & 8.28 & 7.34 & 10.71 & 9.64 \\
\hline 9 & 4 & 7 & 1.34 & 1.32 & 2.60 & 2.46 & 4.40 & 4.20 & 6.14 & 5.99 & 7.97 & 7.75 & 10.24 & 9.84 \\
\hline 10 & 5 & 3 & 1.49 & 1.30 & 2.21 & 2.55 & 3.58 & 4.26 & 5.17 & 6.07 & 6.87 & 8.10 & 9.08 & 10.64 \\
\hline 11 & 5 & 8 & 1.28 & 1.39 & 2.45 & 2.30 & 3.92 & 3.78 & 5.37 & 5.31 & 6.88 & 7.07 & 8.76 & 9.24 \\
\hline 12 & 4 & 3 & 1.32 & 1.34 & 2.32 & 2.61 & 3.80 & 4.16 & 5.20 & 5.86 & 6.76 & 7.63 & 8.74 & 9.79 \\
\hline All & 25 & 26 & 1.39 & 1.37 & 2.43 & 2.43 & 4.03 & 4.03 & 5.65 & 5.67 & 7.42 & 7.49 & 9.61 & 9.70 \\
\hline
\end{tabular}

†Standard error of a man can be obtained by dividing $\sqrt{n}$ into $0.188,0.224,0.375,0.528,0.693$ or 0.844 for weights on days $0,7,14,21$, 28 or 35 , respectively.

‡H represents horizontal bar crates. $\mathrm{V}$ vertical bar crates.

\section{Aspects of Variation in Piglet Weights}

Examples of within-litter variation in piglet weight gain are presented in Fig. 1 which shows one litter with very uniform weight gains and two litters with highly variable gains. In all three litters, the piglets that gained most quickly tended to have a nearly linear pattern of weight increase over the 5 wk. However, the two more variable litters included piglets with very poor gains. For these animals, weight gain was slow until about $21 \mathrm{~d}$, and then increased (though never matching their fast-gaining littermates) from days 21 to 35.

These trends are clearly shown in Fig. 2 which illustrates average growth curves of piglets classified according to 21-d weight. Piglets with the lowest 21-d weights show a clear curve in their pattern of weight change, while those with the highest 21-d weights show a nearly linear pattern of gain.

For many traits in nature, the standard deviation is positively correlated with the mean. This was true of within-litter standard deviation in initial weights $(r=0.48)$, but any association disappeared at the later ages (Table 3). This was not because the litters were more uniform at the later ages; in fact, the 51 litters were more uniform relative to the mean on day 0 (average coefficient of variation $=14.6 \%$ than at any later age (average $\mathrm{CV}=17.8$ to $20.7 \%$ at five subsequent ages). Furthermore, within-litter standard deviation at the later ages was not simply a reflection of within-litter standard deviation in initial weight. Up to $14 \mathrm{~d}$ of age, there was a moderate relationship between within-litter standard deviation and the initial value, but by weeks 3-5, the correlation had become small $(r<0.32$, Table 3$)$.

It is well established that initial weight accounts for about $30-40 \%$ of within-litter variation in weight at 2-3 wk of age (McBride et al. 1965: Scheel et al. 1971; Fraser et al. 1979; Fraser and Thompson 1986). The present data enabled a more detailed examination of how this relationship develops with age. As shown in Table 4, 0-d weight was a moderately good predictor of 7 -d weight $\left(r^{2}=0.57\right)$, but its value as a predictor of weight at later ages declined steadily to $21 \mathrm{~d}$ and slowly thereafter. By $21 \mathrm{~d}$, body weight at a given age was an excellent predictor $\left(r^{2}>0.90\right)$ of weight a week later. Separate analyses were done to determine whether the percentage variation explained $\left(r^{2}\right)$ varied according to crate type or litter size, but there were no marked differences. 
Table 2

Mean† within-litter variance in body weight at 0, 7, 14, 21, 28 and $35 \mathrm{~d}$ (after adjusting 7- to 35-d weights for 0-d weight)

\begin{tabular}{|c|cc|cc|cc|cc|ccc|c|}
\hline & \multicolumn{2}{|c|}{ Day 0 } & \multicolumn{2}{|c|}{ Day 7 } & \multicolumn{2}{c|}{ Day 14 } & \multicolumn{2}{c|}{ Day 21 } & \multicolumn{2}{c|}{ Day 28 } & \multicolumn{2}{c|}{ Day 35 } \\
\cline { 2 - 12 } Litter size & $\mathbf{H}$ & $\mathbf{V}$ & $\mathbf{H}$ & $\mathbf{V}$ & $\mathbf{H}$ & $\mathbf{V}$ & $\mathbf{H}$ & $\mathbf{V}$ & $\mathbf{H}$ & $\mathbf{V}$ & $\mathbf{H}$ & $\mathbf{V}$ \\
\hline 8 & 0.045 & 0.059 & 0.115 & 0.054 & 0.657 & 0.298 & 1.415 & 0.736 & 2.203 & 1.013 & 2.880 & 1.485 \\
9 & 0.046 & 0.033 & 0.058 & 0.079 & 0.270 & 0.394 & 0.623 & 0.908 & 0.977 & 1.417 & 1.235 & 2.017 \\
10 & 0.052 & 0.040 & 0.150 & 0.065 & 0.757 & 0.240 & 1.963 & 0.462 & 3.087 & 0.642 & 4.854 & 1.223 \\
11 & 0.050 & 0.047 & 0.096 & 0.074 & 0.421 & 0.389 & 0.921 & 1.006 & 1.267 & 1.647 & 1.929 & 2.718 \\
12 & 0.025 & 0.053 & 0.103 & 0.083 & 0.423 & 0.280 & 0.887 & 0.720 & 1.472 & 0.752 & 2.193 & 1.649 \\
All & 0.044 & 0.046 & 0.107 & 0.072 & 0.530 & 0.343 & 1.215 & 0.832 & 1.880 & 1.244 & 2.711 & 1.996 \\
\hline
\end{tabular}

†An approximate standard error of a mean can be obtained by dividing $\sqrt{n}$ ( $n$ is number of litters shown in Table 1) into $0.027,0.053,0.272,0.682,1.101$, or 1.656 for values on days $0,7,14,21,28$ or 35 , respectively.

$\ddagger \mathrm{H}$ represents horizontal bar crates. $\mathrm{V}$ vertical bar crates.

Fig. 1. Examples of weight gains of piglets in three litters of eight or nine piglets. Litter 3 (at left) had the lowest within-litter variance in 35-d weight; litters 48 and 55 (center and right) had among the highest. For each litter, weights are shown for piglets ranked $1^{\text {st }}, 3^{\text {rd }}, 5^{\text {th }}, 7^{\text {th }}$ and last in the litter, based on 35-d weight.

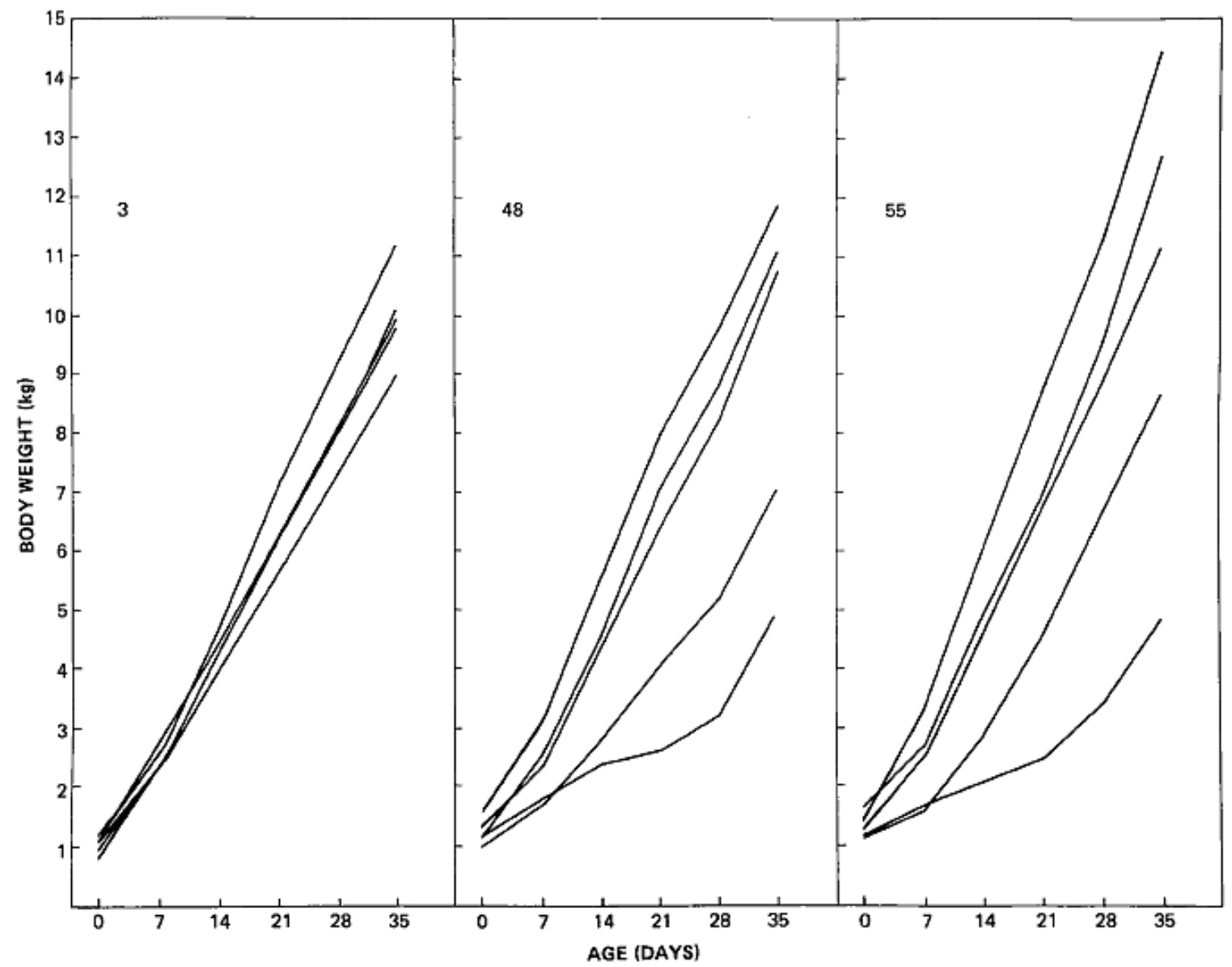

The development of variation in piglet weights is further illustrated in Fig. 3. Weekly percentage weight increase (i.e., weight gain during a given week as a percentage of body weight at the beginning of the week) was extremely variable for young piglets. In the first week after birth, piglets gained from 9 to $180 \%$ 
of their initial weight (mean \pm SD of $77.4 \% \pm 27.5 \%$ ). In the second week, percentage gain was still relatively large and quite variable $(65.8 \% \pm 17.2 \%)$. Thereafter, weight gains during a given week tended more and more to be a relatively fixed percentage of body weight at the beginning of the week (e.g., $30 \%$ $\pm 7.8 \%$ in the fifth week).

Table 3. Correlations at various ages between within-litter standard deviation in body weight and (a) litter mean body weight, and (b) within-litter standard deviation in initial (0-d) weight

\begin{tabular}{|ccc|}
\hline & \multicolumn{2}{c|}{$\boldsymbol{r}$} \\
\cline { 2 - 3 } Age (d) & Within-litter standard deviation vs. litter mean & $\begin{array}{c}\text { Within-litter standard deviation vs. within- } \\
\text { litter standard deviation on d 0 }\end{array}$ \\
\hline 1 & $0.48 \dagger$ & -- \\
7 & 0.13 & 0.61 \\
14 & 0.13 & 0.44 \\
21 & -0.025 & 0.31 \\
28 & -0.007 & 0.30 \\
35 & -0.075 & 0.26 \\
\hline
\end{tabular}

†All values based on the 51 litter means and standard deviations without adjustment for 0-d weight.

Fig. 2. Growth curves (based on mean values of weekly weighings) for 488 piglets divided according to 21-d weight: group A were $<3 \mathrm{~kg}$ at $21 \mathrm{~d}$, group B were $3-4 \mathrm{~kg}$, C were $4-5 \mathrm{~kg}$, D were 5-6 kg, E were 6-7 kg and F were $>7 \mathrm{~kg}$.

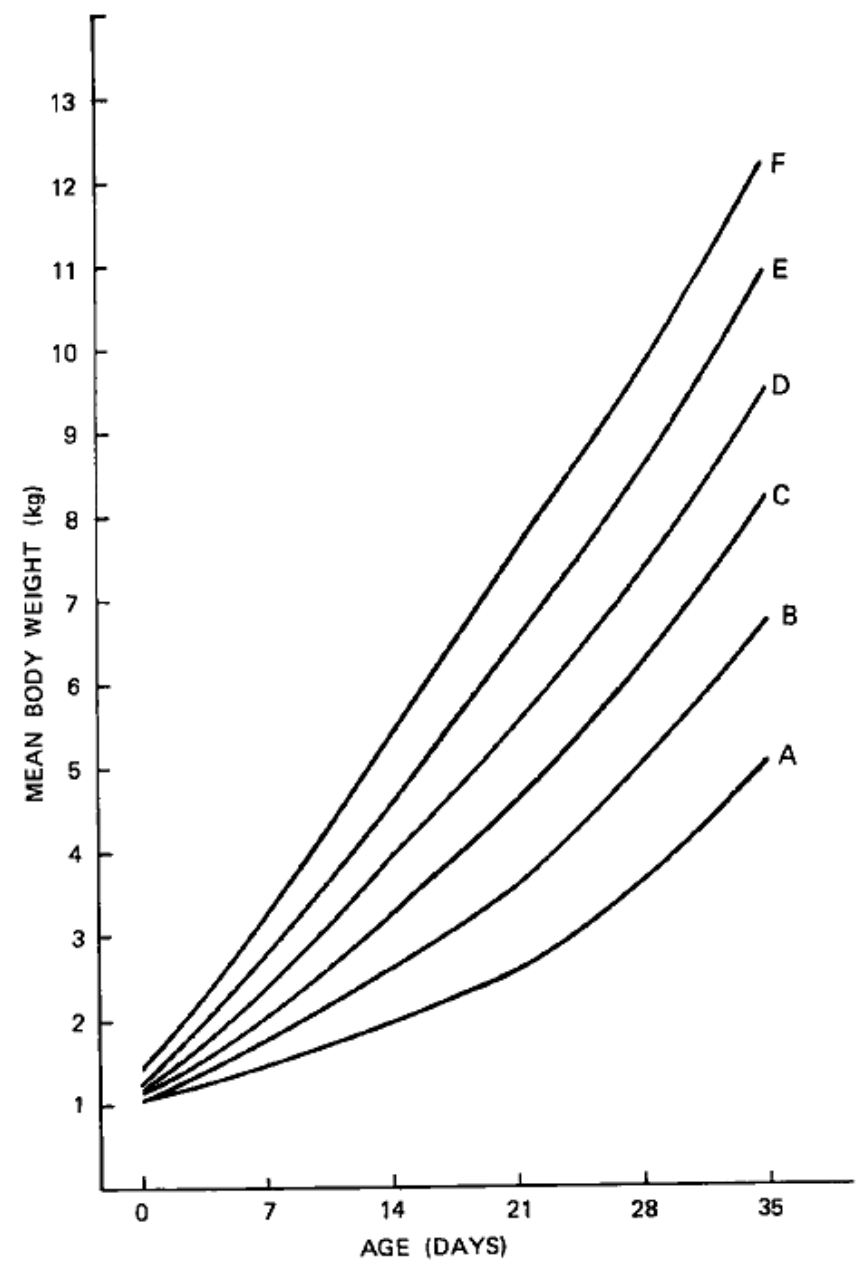


Fig. 3. Weekly weight gain (expressed as a percentage of body weight at the beginning of the week) in relation to initial body weight, shown for $\mathbf{4 8 8}$ piglets over 5 separate wk of lactation.

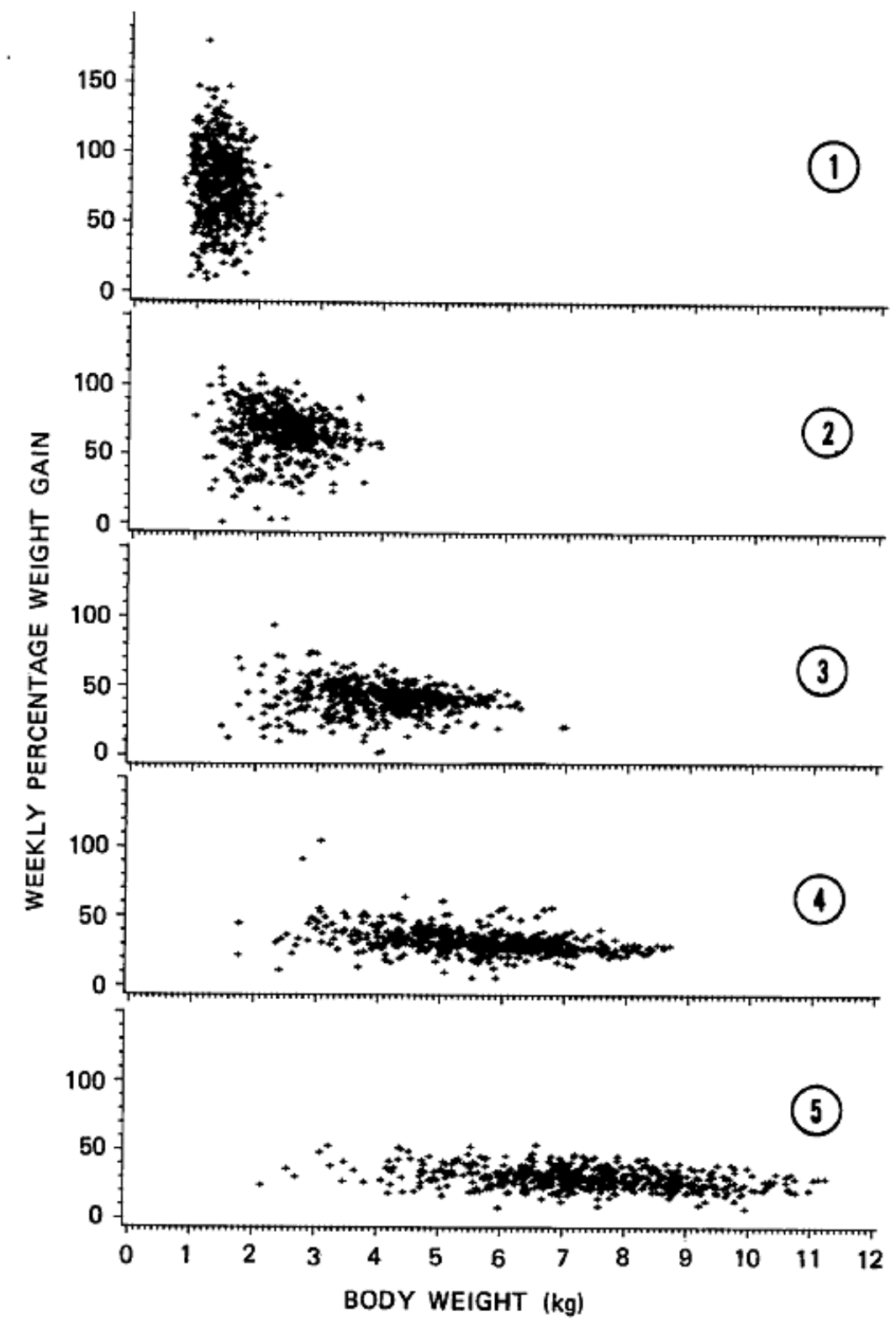

Table 4. Percentage of within-litter variation in 7- to 35-d weights explained by 0 -d weight and by weight the previous week

\begin{tabular}{|ccc|}
\hline & \multicolumn{2}{c|}{ Percentage variation accounted for by } \\
\cline { 2 - 4 } Age (d) & 0-d weight & Previous week's weight \\
\hline 7 & $57 \dagger$ & 57 \\
14 & 39 & 82 \\
21 & 30 & 92 \\
28 & 29 & 95 \\
35 & 27 & 94 \\
\hline
\end{tabular}

†All values are squares of correlation coefficients based on 488 piglets. 
The one small exception to this pattern is that in weeks 4 and 5 very small piglets tended to gain a slightly higher percentage of initial weight than the larger piglets (Fig. 3). In these weeks, weekly percentage weight gain showed a somewhat larger negative correlation with weight at the beginning of the week, as compared with the correlations in earlier weeks $(r=-0.38$ and -0.33 for weeks 4 and 5 , respectively, vs. $r$ $=-0.12,-0.09$ and -0.13 for weeks $1-3$, respectively). This further reflects the tendency for the smallest piglets to have an accelerating growth curve after $21 \mathrm{~d}$ of age, as shown in Fig. 2.

\section{Effect of Competition among Littermates}

The results also reflected the development of within-litter competition as a factor influencing piglet weight change. As competition can only occur within litters, it might be expected to cause the regression of subsequent (i.e., 7- to 35-d) weight on 0-d weight to have a steeper slope within litters than between litters. Regression analysis (Table 5) showed the within- and between-litter slopes to be virtually the same for day 7 , but thereafter the difference between the two increased at each measurement date, with the within-litter slopes significantly steeper at $21 \mathrm{~d}(P<0.025), 28 \mathrm{~d}(P<0.005)$ and $35 \mathrm{~d}(P<0.01)$.

\section{DISCUSSION}

As in our previous study (Fraser and Thompson 1986), farrowing crate design seems to have influenced within-litter variance in piglet weights at $14 \mathrm{~d}$. In both studies, the within-litter variance was significantly higher with horizontal-bar crates than with vertical-bar crates. The reasons for this difference are not completely clear. Possibly the impeded access to the udder in the horizontal-bar crate may have increased the difficulty in suckling behavior experienced by the less competitive piglets, causing reduced milk intake by these animals. Assuming that the sow's total milk production was not reduced, this should lead to increased milk intake by the more competitive piglets and thus cause increased variation in weight gain, without necessarily affecting the litter mean. Edwards and Lightfoot (1985) also found no difference in mean piglet weight gain when they compared farrowing crates similar to ours, but they did not analyze within-litter variation.

After $14 \mathrm{~d}$, the effect of farrowing crate design on within-litter variation tended to wane. This may reflect the fact that piglet weight gains are influenced more and more by intake of supplementary solid feed after $14 \mathrm{~d}$ (see Fraser (1978)). Intake of solid feed may explain why the piglets with low 21-d weight (presumably caused by low milk intake) had an upward trend in their growth curves from days 21 to 35 (Figs. 1 and 2).

A puzzling result is the significant interaction of farrowing crate design and litter size with mean litter weights. As the piglets grew older and larger, crowding during suckling behavior may have become more severe, especially in the larger litters with horizontal-bar crates. This could explain why weights at 21-35 d appeared to be poorer with horizontal bars in litters of 10-12 piglets. However, we can see no reason why the horizontal bars should have a beneficial effect in litters of 8 and 9. Interestingly, in both this and a previous study (Fraser and Thompson 1986), the expected linear trend of mean body weight on litter size was much more marked in horizontal-bar crates than in vertical. Perhaps some of this linear trend, usually attributed to limitation in the sow's milk supply, is actually due to crowding among litter-mates during suckling, with this effect more pronounced if access to the udder is made difficult by the farrowing crate.

The scatter diagram (Fig. 3) shows that much of the variation in piglet weight gains is associated with events occurring in the first week, and to a lesser extent the second week, after birth. During this time, weight gain is not closely correlated with initial weight, and gains are extremely variable. Thereafter, weight gains in a given week tend more and more to be a fixed percentage of body weight at the 
beginning of the week: that is, gain tends to be proportional to weight. Consequently, the differences established in the first $2 \mathrm{wk}$ tend to be perpetuated and amplified in weeks 3-5.

Table 5. Regression slope ( \pm SE) of 7 - to 35 -d weight on 0 -d weight, calculated on a within-litter and a between-litter basis

\begin{tabular}{|ccc|}
\hline Age (d) & Within litters & Between litters \\
\hline 7 & $1.63 \pm 0.064$ & $1.56 \pm 0.188$ \\
14 & $2.49 \pm 0.141$ & $1.56 \pm 0.302$ \\
21 & $3.14 \pm 0.216$ & $2.03 \pm 0.408$ \\
28 & $3.76 \pm 0.266$ & $1.94 \pm 0.508$ \\
35 & $4.36 \pm 0.328$ & $2.42 \pm 0.640$ \\
\hline
\end{tabular}

Competition among litter-mates is often cited as a factor influencing piglet weight gain and survival (English et al. 1977; Fraser et al. 1979). However, it may be useful to distinguish between two different forms of competition which we could call direct and indirect. By direct competition we mean the actions of the litter which cause some piglets to be completely or partially excluded from the udder, with the result that they fail to establish normal, regular suckling behavior. This may be a major cause of death, especially for small piglets in large litters. Such competition presumably takes its greatest toll in the first few days after farrowing when mortality rates are highest, although not all affected piglets would be expected to die. In contrast, the difference in slope within and between litters in the regression analyses (Table 5) may reflect a form of indirect competition for milk involving piglets whose suckling behavior is apparently normal and orderly. If we assume that there is an upper limit on the sow's milk production, then extra milk intake by one piglet will be achieved at the expense of other piglets in the litter. Thus, if a larger piglet can stimulate its teat to greater productivity (by more vigorous massage, more thorough draining of the teat, or whatever), the other litter-mates will be expected to receive less than they otherwise would. Evidence of such an effect was not apparent by day 7, but became increasingly strong at days 14-28 (Table 5), perhaps because milk intake limited weight gain more severely as the piglets grew larger.

Whatever the mechanism, the steeper regression slopes within litter than between litter (Table 5) indicate that the weight of a pig at birth relative to its litter mates may have a considerable impact on future gain, regardless of the absolute weight. This is consistent with the result of Fraser et al. (1979) who found that piglets fostered with smaller litter-mates did appreciably better than similar sized piglets fostered with larger litter-mates. Of the 30-40\% of variation in 2- to 3-wk weight explained by differences in birth weight, a sizeable fraction probably reflects within-litter competition.

In agricultural research, there is a tendency to pay attention to means, and to regard variation as a byproduct of experimentation which complicates the interpretation of results. However, as implied by the quotation from English et al. (1971) above, within-litter variation in body weight is itself a trait relevant to piglet production. Drawing on the present and previous studies, it would appear that within-litter variation in body weight (at, say, 14-35 d) is not simply a reflection of the litter mean and variation in initial weight (Table 3). Within-litter variation is apparently influenced by farrowing crate design but not by litter size (Table 2; also Fraser and Thompson (1986)); it varies significantly among dams, and increases with parity number (Fraser and Thompson 1986); and it appears to be influenced by competition among litter-mates for milk. A thorough understanding of within-litter variation will likely require detailed study of events in the first 2 wk after birth. 


\section{ACKNOWLEDGMENTS}

We are grateful to B. A. Campbell for excellent technical collaboration, and to the staff of the A.R.C. pig unit for their kind assistance throughout the study. We also wish to thank the referees for their useful comments concerning the manuscript.

\section{REFERENCES}

Edwards, S. A. and Lightfoot, A. L. 1985. Effects of farrowing crate design and floor type on pig performance and leg and teat damage. Anim. Prod. 40: 545 (Abstr.).

English, P. R., Smith, W. J. and Maclean, A. 1977. The sow -- improving her efficiency. Farming Press, Ipswich, U.K.

Fraser, D. 1978. Observations on the behavioral development of suckling and early-weaned piglets during the first six weeks after birth. Anim. Behav. 26:22-30.

Fraser, D. and Thompson, B. K. 1986. Variation in piglet weights: Relationship to suckling behavior, parity number, and farrowing crate design. Can. J. Anim. Sci. 66:31-46.

Fraser, D., Thompson, B. K., Ferguson, D. K. and Darroch, R. L. 1979. The "teat order" of suckling pigs. III. Relation to competition within litters. J. Agric. Sci. (Camb.) 92: 257-261.

McBride, G., James, J. W. and Wyeth, G. S. F. 1965. Social behaviour of domestic animals. VIL Variation in weaning weight in pigs. Anim. Prod. 7: 67-74.

Scheet, D. E., Graves, H. B. and Sherritt, G. W. 1977. Nursing order, social dominance and growth in swine. J. Anim. Sci. 45: 219-229.

Snedecor, G. W. and Cochran, W. G. 1967. Statistical methods. 6th ed. The lowa State University Press, Ames, lowa.

Zschorlich, B. and Ritter, E. 1984. Der Einfluss der Geburtsmassevarianz auf die Ferkelentwicklung in Ammenwiirfen. 2. Mitteilung: Die Masseentwicklung der Ferkel. Arch. Tierzucht. Berlin 27: 381-393. 